\title{
Safety and efficacy of Neodymium-Yag laser photocoagulation: an experimental study in dogs
}

\author{
P RUTGEERTS, G VANTRAPPEN, K GEBOES, AND L BROECKAERT \\ From the Department of Medicine and Department of Medical Research, University Hospital, St. Rafaël, \\ University of Leuven, Leuven, Belgium
}

SUMMARY Acute and chronic experiments were carried out in 26 beagle dogs to study the safety and efficacy of Neodymium-Yag laser photocoagulation in the treatment of bleeding gastric lesions. Continuous high power (50-60 W) Neodymium-Yag laser photocoagulation applied to the exposed stomach of the dog produced evaporation lesions that reached the muscle layer after six to 10 seconds and caused free perforation after 10 to 12 seconds. The tissue damage caused by these long lasting exposures was closely related to the working distance. Moreover, long pulses of high power photocoagulation were not always effective in stopping experimentally induced gastric bleedings. Short pulses $\left(\frac{1}{2}-1 \mathrm{~s}\right)$ of very high power $(60-70 \mathrm{~W})$ caused less tissue evaporation, which reached the muscle layers only after 14 to 18 pulses and caused free perforation after 22 to 24 pulses. The tissue damage was not related to the working distance when short pulses were used. Repeated shots of high power Yag laser radiation always resulted in stopping the experimental bleedings without deep injury. It is concluded that high power Neodymium-Yag laser photocoagulation is safe and may be used with success in the treatment of bleeding gastric lesions if the radiation is performed in shots of short duration ( $1 \mathrm{~s}$ or less). Clinical studies in man are warranted and indicated.

Fibreoptic coupled Neodymium-Yag lasers have already been used in the treatment of gastrointestinal haemorrhages in man. ${ }^{1}$

These Nd:Yag lasers deliver high power and the laser beam penetrates deep into the stomach wall, the depth of penetration being determined by the wavelength of the beam and the absorptivity of the tissue. Animal studies ${ }^{2}$ have shown that Nd:Yag laser photocoagulation is an effective method of controlling experimental gastric bleeding lesions, but these Yag laser photocoagulations, producing haemostasis, cause full-thickness muscle injury. Therefore, low power argon laser photocoagulation, which carries a lower risk of transmural injury, has been advocated. ${ }^{45}$

Gas-jet assisted laser wave guides have been developed to increase the success rate of laser treatment of bleeding lesions. They decrease the power needed for coagulation and thus diminish the risk of transmural injury. ${ }^{6}$ Although several studies 6 7 have shown that argon lasers are in vitro as effective as $\mathrm{Nd}: Y a g$ lasers in treating experimental bleeding

Received for publication 23 October 1980. ulcers in dogs, low energy lasers, ${ }^{8}$ in contrast to $\mathrm{Nd}$ :Yag lasers ${ }^{9}$ have not yet been shown to be capable of stopping arterial bleeding in man.

The aim of the present study was to evaluate the importance of power and exposure time for the efficacy and safety of $\mathrm{Nd}$ :Yag laser treatment.

\section{Methods}

The Nd:Yag laser apparatus (Medilas-MBB) used in this study delivered a maximum power of $90 \mathrm{~W}$. The power was transmitted for $\pm 84 \%$ by a triconical quartz Nath fibre, ${ }^{1011}$ introduced into the small biopsy channel of an Olympus gastroscope TGF-2D. Water lavage of bleeding lesions was performed through the large channel of the endoscope by means of a high pressure pistol. A jet of $\mathrm{CO}_{2}$ was delivered through a small cleansing channel, with a continuous flow rate of $75 \mathrm{ml} / \mathrm{s}$ during laser application. Twenty-six beagle dogs weighing $12-16 \mathrm{~kg}$, were used for the experiments.

\section{ACUTE EXPERIMENTS}

Acute experiments were carried out in 16 dogs. 
Laser photocoagulations on intact stomach mucosa These were carried out in eight dogs to determine the maximal acute injury that can be caused to the tissue when no laser power was being removed by streaming blood. Under pentobarbitone anaesthesia $(25 \mathrm{mg} / \mathrm{kg})$ a median laparotomy and a gastrostomy were performed and careful haemostasis was effected. Lesions were produced by continuous photocoagulations of 50 and $60 \mathrm{~W}$, by $1 \mathrm{~s}$ interval exposures of $60 \mathrm{~W}$, and by $0.5 \mathrm{~s}$ interval exposures of $70 \mathrm{~W}$. The interval between the exposures in these and in all other experiments using interval exposures was $5 \mathrm{~s}$. The hand-held tip of the endoscope was at a distance of 1.2 to $1.5 \mathrm{~cm}$ from the mucosa. The maximal energy density applied to the mucosa was $1100 \mathrm{~J} / \mathrm{cm}^{2} / \mathrm{s}, 1300 \mathrm{~J} / \mathrm{cm}^{2} / \mathrm{s}$, and $1550 \mathrm{~J} / \mathrm{cm}^{2} / \mathrm{s}$ with 50,60 , and $70 \mathrm{~W}$ respectively.

During these experiments a thermistor was placed in close contact with the serosa of the exposed stomach and temperatures were recorded during laser photocoagulation.

To evaluate the effect of the working distance on the depth of injury, a series of photocoagulations was applied with the tip of the fibre at a distance of $20,15,10$, and $5 \mathrm{~mm}$. When $60 \mathrm{~W}$ power was used in continuous exposures or in $1 \mathrm{~s}$ pulses the energydensities delivered to the tissues varied between 870 and $2200 \mathrm{~J} / \mathrm{cm}^{2} / \mathrm{s}$. Seventy Watt pulses of $0.5 \mathrm{~s}$ delivered between $1017-2600 \mathrm{~J} / \mathrm{cm}^{2} / \mathrm{s}$.

\section{Laser treatment of experimental ulcers}

In eight heparinised dogs (sodium heparin: 200 USP/kg) experimental ulcers were made with an ulcer maker of the type used by Protell et al..$^{12}$ The average ulcer diameter was $8 \mathrm{~mm}$ (SEM 0.41) and the average depth $1.4 \mathrm{~mm}$ (SEM 0.11). The ulcers reached to the middle third of the submucosa. Bleeding was quantified as proposed by Silverstein et al. (1977) and the ulcers were divided into three groups according to the rate of bleeding: mild $<1 \mathrm{ml} / \mathrm{min}$; moderate: $1-3 \mathrm{ml} / \mathrm{min}$; and severe: $>3 \mathrm{ml} / \mathrm{min}$. The following treatment schedules were tested: $50 \mathrm{~W}, 4 \mathrm{~s}$ pulses (maximum 8); $60 \mathrm{~W}, 3 \mathrm{~s}$ pulses (maximum 5); $60 \mathrm{~W}, 1 \mathrm{~s}$ pulses (unlimited), and $70 \mathrm{~W}, 0.5 \mathrm{~s}$ pulses (unlimited). The working distance was $15 \mathrm{~mm}$. The treatment ulcers were observed for at least 10 minutes to detect recurrence of bleeding. The serosa was also carefully examined. After the experiment the dogs were killed, each gastric lesion was resected separately, oriented, and fixed in a Bouin's solution. Paraffin sections were made, stained with haematoxylin-eosin, and examined microscopically.

CHRONIC EXPERIMENTS

Chronic experiments were carried out in 10 dogs.
Endoscopic laser photocoagulations on intact musosa These were carried out in seven dogs. Lesions were produced by $60 \mathrm{~W}$ pulses of 2-8s duration, by 2 to 8 pulses of $60 \mathrm{~W}$ and $1 \mathrm{~s}$, and by 2 to 8 pulses of $0.5 \mathrm{~s}$ and $70 \mathrm{~W}$. The working distance was kept constant at $2.0 \mathrm{~cm}$ by introducing a measuring device into the large channel of the gastroscope. These exposures were repeated at intervals so that when the dogs were killed 15 days after the first laser application, lesions in different stages of evolution were obtained - that is, acute lesions, as well as lesions produced one, four, seven, 10, and 15 days earlier.

\section{Endoscopic treatment of bleeding lesions}

In three heparinised dogs 60 bleeding lesions were produced endoscopically by taking six to eight biopsies on the same spot with a $8 \mathrm{~mm}$ diameter biopsy forceps. After water cleansing 15 lesions were photocoagulated using $50 \mathrm{~W}$ and $4 \mathrm{~s}$ exposures, 15 lesions were treated by $60 \mathrm{~W}$ and $3 \mathrm{~s}$ exposures, 15 lesions by $60 \mathrm{~W}$ and $1 \mathrm{~s}$ exposures, and 15 lesions by $70 \mathrm{~W}$ and $0.5 \mathrm{~s}$ exposures. The exposures were continued until the bleeding was stopped. The dogs were allowed to recover, and were killed two weeks after the experiments.

\section{Results}

\section{ACUTE LESIONS}

Continuous 50-60 W laser photocoagulation of intact gastric wall

This procedure in the dog caused an ulceration after $2 \mathrm{~s}$. The ulcer was confined to the submucosa $(<60 \%$ wall thickness injury) when the exposure time was kept below 6-10 s. With longer exposures the ulcer base perforated the muscle layers and reached the

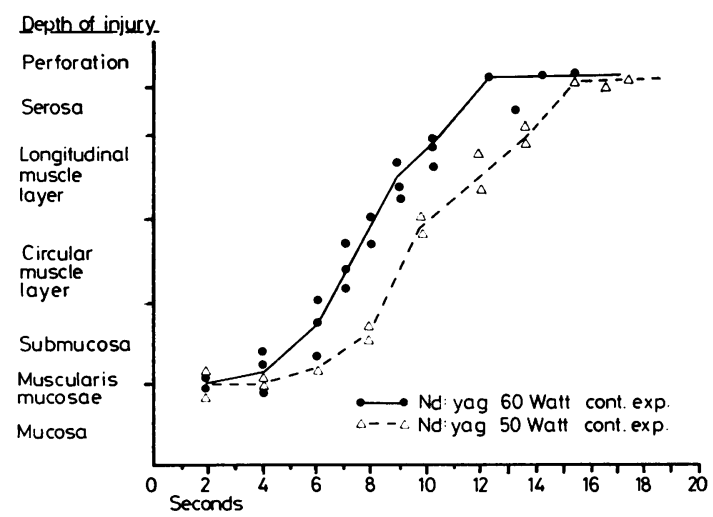

Fig. 1 Depth of injury-that is, base of the evaporation ulcer-caused by continuous Nd:Yag laser photocoagulation related to the applied power and exposure time. 


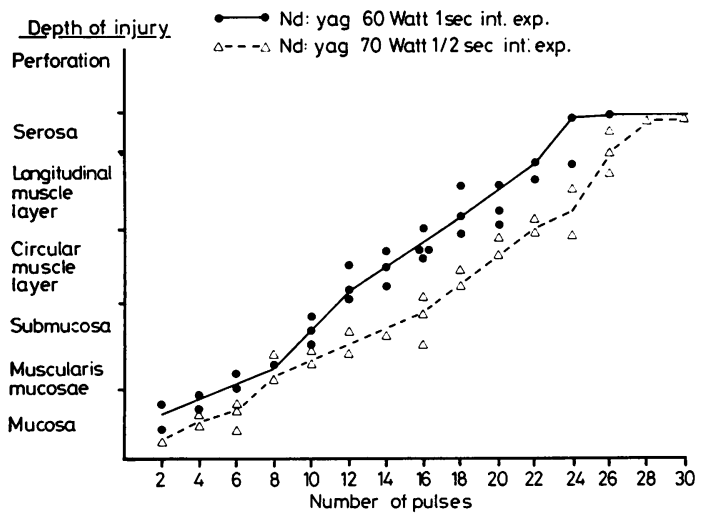

Fig. 2 Depth of injury caused by short pulses of Nd:Yag laser photocoagulation related to the applied power and the number of pulses.

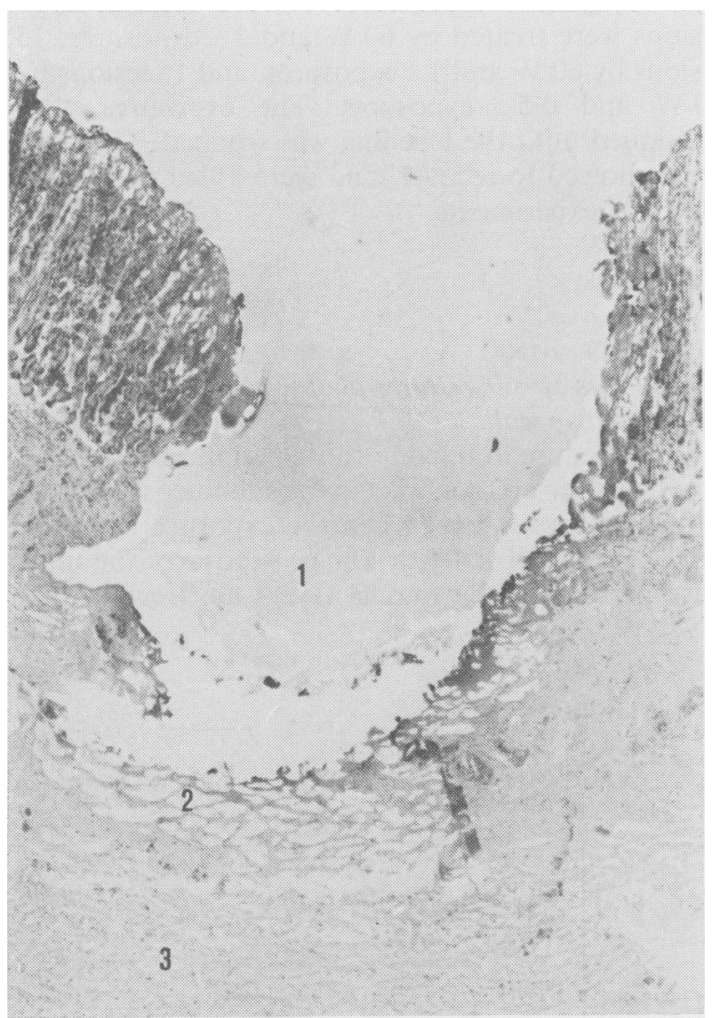

Fig. 3 Acute laser ulcer of the stomach. The thermal effect in the tissue may be divided into three zones: (1) in the inner zone the tissue is completely evaporated; (2) the middle zone consists of dehydrated and partly carbonised material interspersed with empty spaces; (3) the outer zone contains morphologically almost normal tissue that, however, may be thermally devitalised. The lesion reaches the middle of the submucosa. $H$ and $E, \times 200$ (original magnification). longitudinal muscle (75-80\% wall thickness injury) after 10-12 s. Free perforation occurred after 12-16 s of continuous exposure. Interval high power (60$70 \mathrm{~W}$ ) photocoagulation using $1 \mathrm{~s}$ or $0.5 \mathrm{~s}$ pulses caused more superficial tissue evaporation. Using $60 \mathrm{~W}$ pulses of $1 \mathrm{~s}$ duration, the muscularis mucosae (15\% wall thickness injury) was perforated after 4 pulses, the circular muscle layer was reached after 14 pulses, the longitudinal layer was perforated after 20 pulses, and free perforation was caused by $241 \mathrm{~s}$ pulses. Using $70 \mathrm{~W}$ and $0.5 \mathrm{~s}$ pulses the ulcer base reached the muscle layers after 18 pulses, penetrated through the longitudinal muscle after 22 to 24 pulses and caused a free perforation after 28 pulses of $0.5 \mathrm{~s}$ (Figs. 1, 2).

On histological examination (Fig. 3) the tissue injury in the acute phase was always limited to the base of the sharply delineated ulcer. In the zone immediately underneath the ulcer base, incomplete vaporisation had taken place, which resulted in dehydrated and partly carbonised cellular material interspersed with empty spaces. With the staining used no intravascular lesions could be demonstrated histologically in the acute stage of the injury.

Continuous $60 \mathrm{~W}$ radiation of the intact stomach mucosa caused a rapid rise in temperature at the serosal side of the open stomach. A temperature of $100^{\circ} \mathrm{C}$ was reached already after $3 \mathrm{~s}$ of continuous exposure (Fig. 4). One second pulses caused a temperature rise to about $70^{\circ} \mathrm{C}$. The temperature remained at that level throughout the series of pulses and decreased slowly after the last pulse (Fig. 5).

The acute injury caused by continuous high power photocoagulation also depended on the distance of the fibretip from the mucosa. After $6 \mathrm{~s}$ of continuous $60 \mathrm{~W}$ exposure at $20 \mathrm{~mm}$ distance, the evaporation ulcer was confined to the submucosa. The same

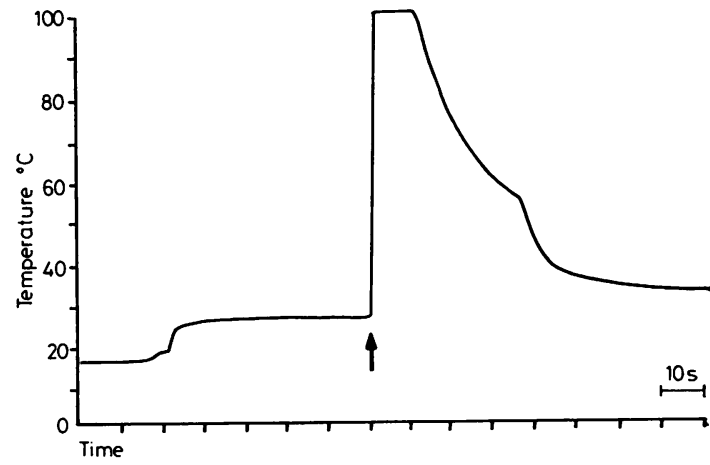

Fig. 4 Temperature (measured with a thermistor at the serosal side of an exposed stomach) produced by $60 \mathrm{~W}$, $12 \mathrm{~s}$ exposure of $\mathrm{Nd}$ : Yag laser photocoagulation of the intact mucosa. 


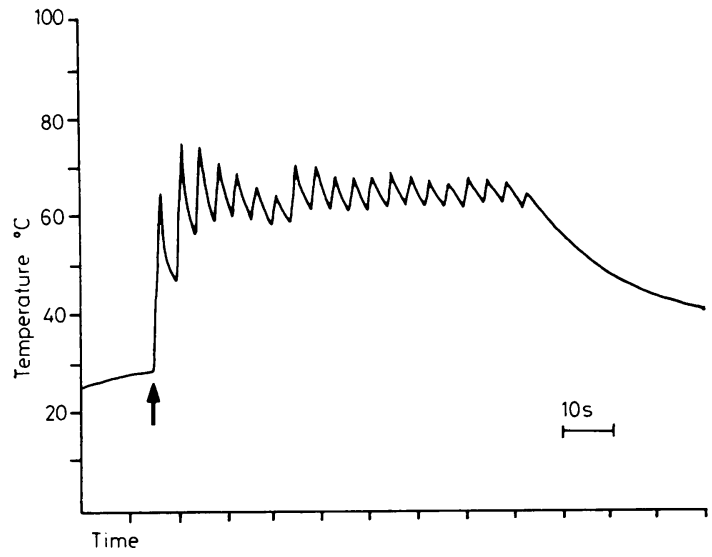

Fig. 5 Temperature (measured with a thermistor at the serosal side of an exposed stomach) produced by 20, $1 \mathrm{~s}$ shots of high power $(60 \mathrm{~W}) \mathrm{Nd}$ :Yag laser photocoagulation on the intact mucosa.

power and exposure time applied from a distance of $15-10 \mathrm{~mm}$ caused an ulcer that reached the circular muscle layer, while the ulcer penetrated down to the longitudinal muscle layer when the working distance was $5 \mathrm{~mm}$. These differences did not occur with interval exposures of 1 or $0.5 \mathrm{~s}$ (Fig. 6).

\section{Treatment of experimentally produced bleeding ulcers}

The data on the results of treatment are summarised in the Table. Fifty Watt power and $4 \mathrm{~s}$ pulses were used to treat 34 bleeding ulcers. Only $69 \%$ of the moderate bleedings and $33 \%$ of the severe bleedings could be controlled. Serosal whitening, indicating full thickness injury, was noted in two maximally treated ulcers. Twenty-one bleeding ulcers were treated by $60 \mathrm{~W}$ power and $3 \mathrm{~s}$ pulses. Only $71 \%$ of the moderate bleedings and $67 \%$ of the severe bleedings could be stopped permanently. In two of

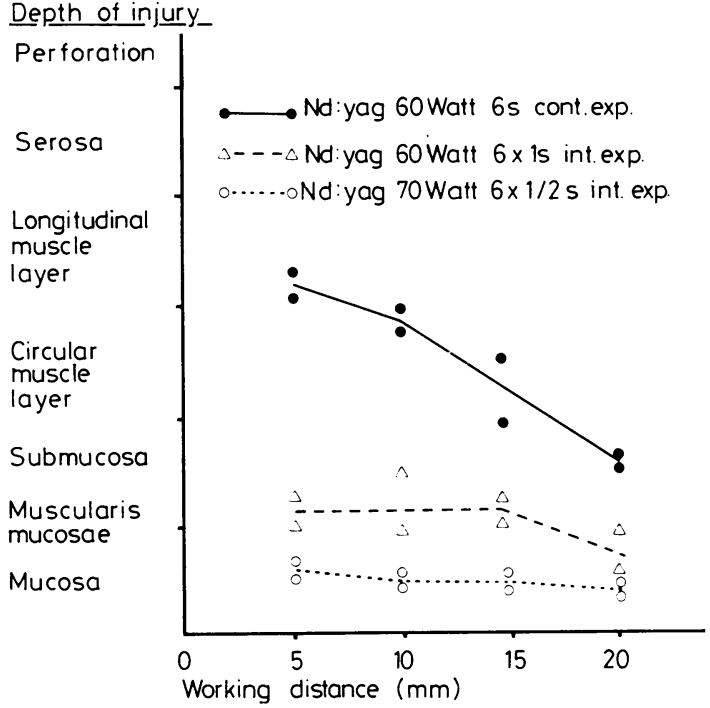

Fig. 6 Depth of injury caused by high power Nd:Yag laser photocoagulation related to the working distance.

these ulcers, treated by the maximum of 5 pulses of $3 \mathrm{~s}$, acute full thickness injury occurred, causing a free perforation in one ulcer.

All 30 bleedings treated by $60 \mathrm{~W}, 1 \mathrm{~s}$ pulses, and all 26 bleedings treated with $70 \mathrm{~W}, 0.5 \mathrm{~s}$ pulses, were controlled. No acute full thickness injury was noted.

At histological examination the injury caused by laser photocoagulation of an experimental bleeding ulcer was found to reach the muscular externa ( $\pm 65 \%$ wall thickness injury) in five out of 34 lesions $(15 \%)$ treated by $50 \mathrm{~W}, 4 \mathrm{~s}$ exposures, and in two out of 21 ulcers $(10 \%)$ treated by $60 \mathrm{~W}, 3 \mathrm{~s}$ exposures. One of the latter ulcers was perforated by the radiation. In the groups treated by $60 \mathrm{~W}, 1 \mathrm{~s}$ exposures and $70 \mathrm{~W}, 0.5 \mathrm{~s}$ exposures the acute injury reached no further than the circular muscle layer.

Table Nd:Yag laser treatment of experimental bleeding ulcers

\begin{tabular}{|c|c|c|c|c|c|c|c|}
\hline Power (W) & $\begin{array}{l}\text { Exposure } \\
\text { time (s) }\end{array}$ & $\begin{array}{l}\text { Bleeding rate } \\
(\mathrm{ml} / \mathrm{min})\end{array}$ & Lesions (no.) & $\begin{array}{l}\text { Bleedings } \\
\text { stopped (no.) }\end{array}$ & Exposures (no.) & Serosal whitening & Perforation \\
\hline \multirow[t]{3}{*}{50} & 4 & $<1$ & 6 & 6 & $1(1-2)$ & - & - \\
\hline & & $1-3$ & 16 & 10 & $5 \quad(2-8)$ & 1 & - \\
\hline & & $>3$ & 12 & 4 & $6 \cdot 3(5-8)$ & 1 & - \\
\hline \multirow[t]{3}{*}{60} & 3 & $<1$ & 8 & 8 & $2(1-3)$ & - & - \\
\hline & & 1-3 & 7 & 5 & $3(2-5)$ & - & - \\
\hline & & $>3$ & 6 & 4 & $4(3-5)$ & 1 & 1 \\
\hline \multirow[t]{3}{*}{60} & 1 & $<1$ & 11 & 11 & $6 \cdot 3(4-7)$ & - & - \\
\hline & & $1-3$ & 8 & 8 & $9 \cdot 3(3-18)$ & - & - \\
\hline & & $>3$ & 11 & 11 & $14(6-22)$ & - & - \\
\hline \multirow[t]{3}{*}{70} & $\frac{1}{2}$ & $<1$ & 6 & 6 & $7(2-12)$ & - & - \\
\hline & & $1-3$ & 10 & 10 & $15(7-22)$ & - & - \\
\hline & & $>3$ & 10 & 10 & $24(17-39)$ & - & - \\
\hline
\end{tabular}




\section{CHRONIC LESIONS}

Photocoagulation of intact stomach wall

Follow-up of these lesions showed that the injury to the wall goes deeper than the acute evaporation ulcer. One day after endoscopic photocoagulation the ulcer depth was comparable with that of the acute lesion and was related to the power and the exposure time used. However, considerable oedema and congestion of the tissue beneath and around the ulcer had developed. Even when the ulcer did not reach the muscle layers, fragmentation of the circular and longitudinal muscles was present at day 4-7 (Fig. 7), as well as macroscopic serositis in all lesions (Fig. 8). Transmural inflammation was much more pronounced when continuous exposures of 50-60 W had been used than when 1 or $0.5 \mathrm{~s}$ pulses of $60-70 \mathrm{~W}$ had been applied, the total exposure time being the same. There was thrombosis of the submucosal vessels with beginning recanalisation. Re-epithelialisation started from the ulcer-edges on day four and was complete after 10 days when interval exposures had been used and after 14 days after continuous exposures. At that time there was considerable fibrosis of the submucosa and the muscu- losa. In none of the more than 100 lesions did late free perforation occur.

\section{Bleeding lesions, caused by multiple endoscopic biopsies}

All such lesions on the same spot in heparinised dogs were easily and successfully treated. All dogs recovered without problems, and at necropsy no serosal lesions were detected.

\section{Discussion}

The aim of therapeutic laser photocoagulation is to stop the haemorrhage by producing coagulation in the submucosal vessels which are usually the source of bleeding. In order to be clinically acceptable, the necrosis produced by the photocoagulation should not carry the risk of perforation of the wall of the viscus. The present studies show that $50-60 \mathrm{~W} \mathrm{Nd}$ : Yag laser photocoagulation cannot safely be used when long continuous exposures are applied. Indeed acute muscle damage occurs after exposures of 6-8 s and acute free perforation after exposures of 12-15 s. With short pulses of high power $(60-70 \mathrm{~W})$ as many as 14 to 18 pulses may be applied before the muscle

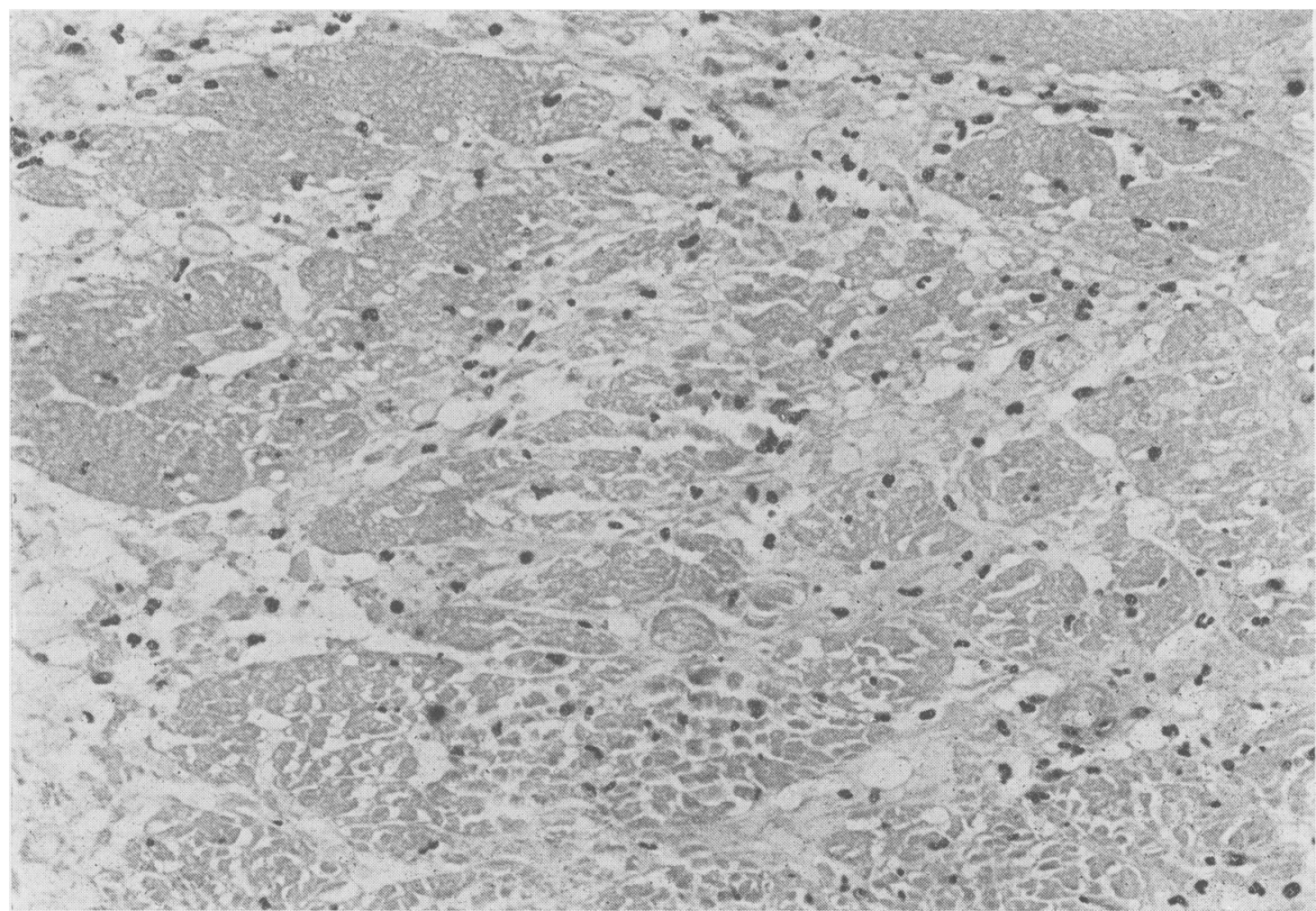

Fig. 7 Oedema, fragmentation, and involution of the muscularis propria in chronic laser photocoagulation experiments, six days after laser photocoagulation. $H$ and $E, \times 500$ (original magnification). 
layer is perforated and 22 to 24 pulses before free perforation occurs.

Using continuous high power photocoagulations the tissue injury depends greatly on the working distance, while with short pulses the working distance is less important.

With continuous exposures the serosal temperature rises above $100^{\circ} \mathrm{C}$ after $3 \mathrm{~s}$, while with short pulses of high power the temperature never exceeds $70^{\circ} \mathrm{C}$. It may be assumed that short pulses of high power laser photocoagulation produce tissue heating ideal for protein coagulation and thrombus formation, while the excessively high temperatures caused by continuous high power photocoagulation cause damage to the vessel wall and increased bleeding, certainly when the evaporation ulcer reaches the submucosal vessels.

The chronic experiments confirm that high power Yag-laser photocoagulations always cause transmural inflammation which is at its height three to seven days after the exposures, as already pointed out by Protell et al. ${ }^{13}$ and Bown et al. ${ }^{14}$ These inflammatory features-that is, fragmentation of the muscle layers and serositis-were much less important when short pulses of $1 \mathrm{~s}$ or less were used. Moreover, in none of the lesions did a late free perforation occur.

The efficacy of high power laser photocoagulation was studied in heparinised dogs in which a bleeding 'ulcer' was made either at operation or through a gastroscope. In both these experimental conditions repeated short pulses of $60-70 \mathrm{~W}$ laser radiation produced significantly better results than longer periods of uninterrupted exposure.

It is concluded that to treat gastrointestinal bleeding very high $(60-70 \mathrm{~W})$ power $\mathrm{Nd}$ :Yag laser photocoagulation must be applied in short $0.5-1 \mathrm{~s}$ pulses. This method of application is highly effective and safe, while tissue damage is unrelated to the working distance, which makes it suitable for endoscopic treatment. Although chronic transmural tissue inflammation is always present after photo-

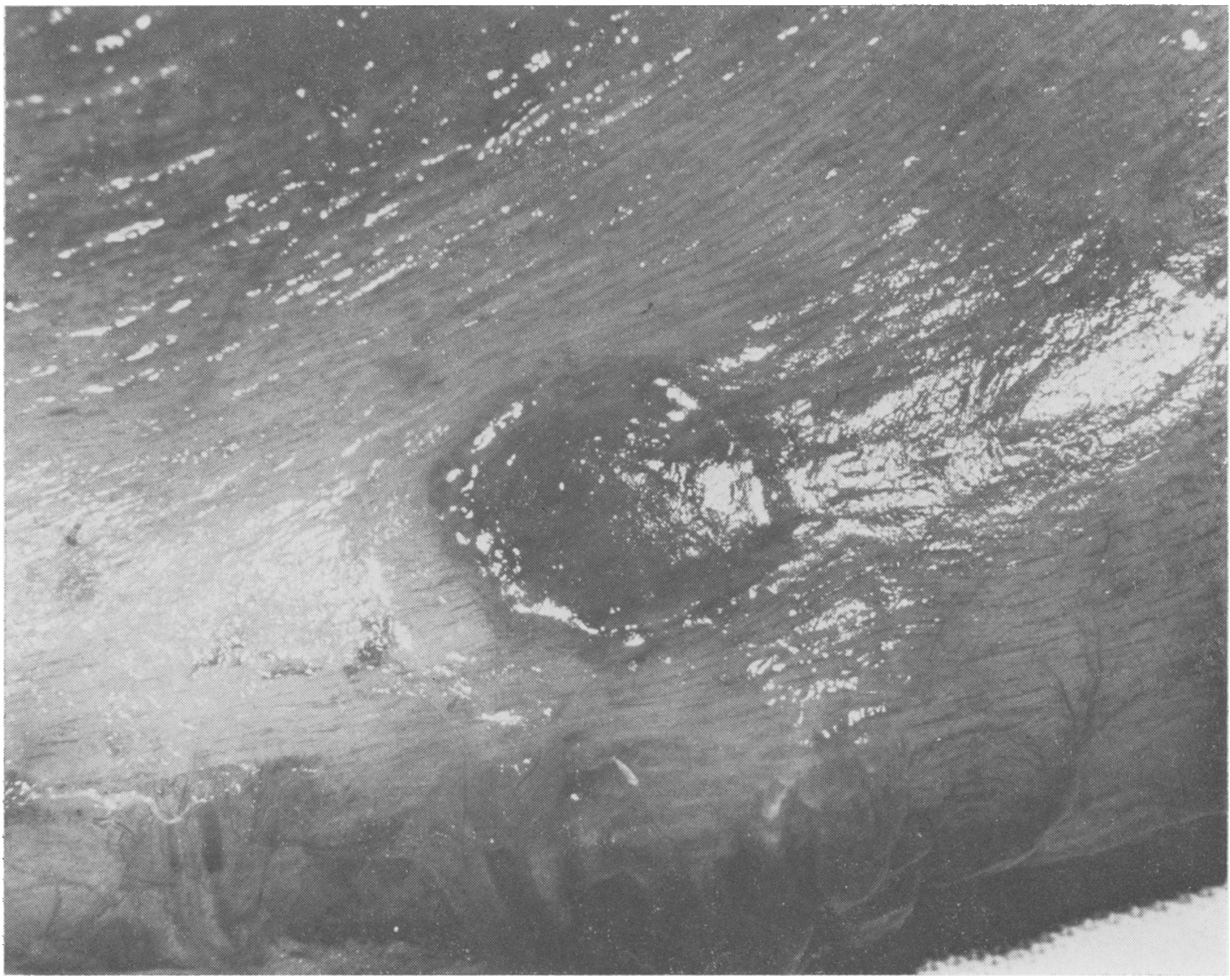

Fig. 8 Macroscopic serositis five days after $60 \mathrm{~W}, 4 \mathrm{~s}$ continuous Nd:Yag laser photocoagulation. 
coagulation, this does not seem to increase the risk of late perforation. These observations indicate that clinical studies with $\mathrm{Nd}$ :Yag laser photocoagulation in short pulses are warranted in man.

\section{References}

${ }^{1}$ Kiefhaber P, Nath G, Moritz K. Endoscopical control of massive gastrointestinal hemorrhage by irradiation with a high-power Neodymium-Yag laser. Prog Surg 1977; 15: 140-55.

${ }^{2}$ Silverstein FE, Protell RL, Gilbert DA, et al. Argon vs. Neodymium Yag laser photocoagulation of experimental canine gastric ulcers. Gastroenterology 1979; 77 : 491-6.

${ }^{3}$ Dixon JA, Berenson MM, McCloskey DW. Neodymium-Yag laster treatment of experimental canine gastric bleeding. Gastroenterology 1979; 77: 647-51.

${ }^{4}$ Frühmorgen P, Kaduk B, Reidenbach HD, Bodem F, Demling L. Vergleichende Untersuchungen zur Fiberendoskopischer Lichtkoagulation mit einem Argonionen- und einem Neodymium Yag-laser. In: Fortschritte der Gastroenterologischen Endoskopie, BadenBaden: Witzrock Verlag, 1976: 219-25.

${ }^{5}$ Silverstein FE, Protell RL, Piercey J, Rubin CE, Auth DC, Dennis M. Comparison of the efficacy of high and low power photocoagulation in control of severely bleeding experimental ulcers in dogs. Gastroenterology 1977; 73: 481-6.

${ }^{6}$ Silverstein FE, Protell RL, Gulacsik C et al. Development and testing of a gas-jet-assisted argon laser wave guide in control of bleeding experimental ulcers. Gastroenterology 1978; 74: 232-9.

${ }^{7}$ Bown SG, Salmon PR, Kelly DF, et al. Argon laser photocoagulation in one dog stomach. Gut 1979; 20: 680-7.

${ }^{8}$ Frühmorgen $\mathrm{P}$, Boden $\mathrm{F}$, Reidenbach $\mathrm{H}$, Kaduk B, Demling L. Klinische Erfahrungen mit einer neuen Methode der Laserkoagulation. Dtsch Med Wochenschr 1976; 101: 1305-7.

${ }^{9}$ Kiefhaber P, Moritz K, Schildberg FW, Feifel G, Herfarth Ch. Endoskopische Nd-Yag Laserkoagulation blutender akuter und chronischer Ulcera. Langenbecks Arch Chir 1978; 367-567.

${ }^{10}$ Nath G, Gorisch W, Keifhaber P. First laser endoscopy via a fiberoptic transmission system. Endoscopy 1973; 5: 208-13.

${ }^{11}$ Nath G, Gorisch W, Kreitmair A, Kiefhaber P. Transmission of a powerful Argon laser beam through a fiberoptic flexible gastroscope for operative gastroscopy. Endoscopy 1973; 5: 213-5.

${ }^{12}$ Protell RL, Silverstein FE, Piercey J, Dennis M, Sprake $\mathrm{W}$, Rubin CE. A reproducible animal model of acute bleeding ulcer-The 'ulcer maker'. Gastroenterology 1976; 71 : 961-4.

${ }^{13}$ Protell RL, Silverstein FE, Auth DC, Dennis MB, Gilbert DA, Rubin CE. The Nd-Yag laser is dangerous for photocoagulation of experimental bleeding gastric ulcers when compared with the argon laser. Gastroenterology 1978; 74: 1080.

${ }^{14}$ Bown SG, Salmon PR, Kelley DF et al. Neodymium Yag laser photocoagulation in the dog stomach. Gut 1979; 20: A434. 